\title{
Wounds Research Network (WReN) - a community of practice for improving wound care-related trials
}

Keywords: trials, wound care, community of practice, Wounds Research Network, universal health coverage

Well-designed trials that generate clinically relevant and robust knowledge are integral to improving health nationwide and achieving universal health coverage. This paper critically analyses the existing challenges associated with improving trials as well as how these challenges can be overcome through a research community of practice, such as the Wounds Research Network.

\begin{abstract}
Poorly designed wound trials that generate knowledge that does not inform clinical practice constitute an example of research waste that undermines evidence-based healthcare. Well-designed trials that generate clinically relevant and robust knowledge are integral to improving health nationwide and achieving universal health coverage.
\end{abstract}

This paper critically analyses the existing challenges associated with improving trials as well as how these challenges can be overcome through a research community of practice, such as the Wounds Research Network (WReN).

Although a wide range of people have a stake in improving wound trials, they often belong to different social or professional groups that can make collaborative work challenging. In the UK, WReN demonstrates how a unifying national research community of practice can help people work together to design and conduct studies that generate knowledge that may help improve patient care.

\section{Key Message}

- Communities of practice such as the WReN are a useful resource for improving wound trials to generate knowledge that informs clinical practice and contributes to the establishment of universal health coverage.

\section{INTRODUCTION}

Poorly designed wound trials that do not generate knowledge that clinicians can utilise to inform patient care constitute an example of research waste, ${ }^{1-4}$ which undermines efforts to deliver person-centred, evidence-based healthcare to all. A lively debate has long surrounded the wound healing community regarding a trial's ability to generate evidence that clinicians may use to inform patient care. ${ }^{5-9}$ The shortcomings and flaws associated with wound-related trials and their inability to generate knowledge that may inform patient care are well known. ${ }^{5,8,10}$ Designing trials that generate clinically relevant knowledge at a national level may be challenging because many people with wounds have other co-morbidities and because healthcare is delivered via complex adaptive systems. ${ }^{7,10,11}$

Quality improvement efforts in complex adaptive systems such as healthcare can fail with disastrous consequences and devastating outcomes. ${ }^{12}$ Poorly designed trials contribute to negative perceptions amongst clinicians, policymakers, researchers, healthcare commissioners, and funders regarding research's ability to improve the quality of wound care and patient outcomes. ${ }^{5,6,10}$ However, the consequences of poorly designed trials extend far beyond wound healing in that they undermine efforts to promote evidence-based healthcare. ${ }^{2,4}$

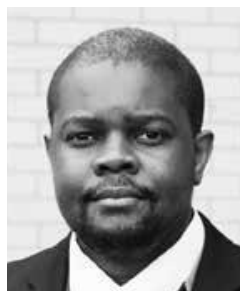

Ray Samuriwo

$\mathrm{PhD}$

School of Healthcare Sciences, Cardiff University, Cardiff, United Kingdom Wales Centre for Evidence Based Care, Cardiff

University, Cardiff, United Kingdom

More informations: www.woundsrn.org

Correspondence: samuriwor@cardiff.ac.uk

Conflicts of interest: Dr Ray Samuriwo is Trustee of the Tissue Viability Society and a member of the Wounds Research Network (WReN) Scientific Committee. However, the views and opinions expressed therein are those of the author and do not necessarily reflect the views or opinions of the Tissue Viability Society or WReN. 
Some have argued ${ }^{6-8}$ that it would be most beneficial to adopt a different approach to evidence-based wound care in which there exists less reliance on evidence from trials and clinical practice is informed by evidence from studies that employ other research methods.

Adopting a broader approach to evidence-based wound care and using other research methods may generate useful insights that inform patient care. However, the global focus is on universal health coverage in which everyone has access to care that is delivered in a just, equitable, and safe manner. ${ }^{13}$ Achieving universal health coverage requires a population approach to healthcare in which the national focus is on improving the health and well-being of every citizen. ${ }^{13}$ Therefore, it is important for researchers and clinicians to consider how wound care trials can be improved to inform patient care at a national level.

This paper examines key elements of the wider debate on improving healthcare-related trials before exploring how wound care trials can be improved through a research community of practice. The nature and purpose of a community of practice is summarised with an exploration into how it might contribute to improved wound trials. The Wounds Research Network (WReN) is then applied as a case study of a community of practice that was created by the Tissue Viability Society to improve wound trials in the UK. This paper concludes with a discussion of how research communities of practice such as the WReN can improve a trials' ability to generate knowledge that helps achieve universal health coverage in wound care.

\section{Improving clinical trials}

Poor trials are not unique to wound care, as many examples exist of research waste caused by poor trials in other aspects of healthcare. ${ }^{2-4}$ Trials can be improved in a variety of ways, such as by creating more appropriate reporting standards, $, 3,14$ improving the methods applied, ${ }^{1,3}$ or improving regulation. ${ }^{15}$ However, the definition of what constitutes a good trial changes over time as new and innovative trial designs emerge. ${ }^{14}$ Therefore, the design and conduct of trials at any given time are socially mediated and defined. In other words, what is considered a good trial at any point in time is strongly influenced by the views of the wider research community. In the rapidly evolving world of research, the prevailing consensus within the research community concerning the most appropriate methods for the design and reporting of trials solely exists until the next methodological innovations emerge. ${ }^{3,14}$ The rapid pace of methodological innovation implies that the consensus as to the best practice regarding the design and conduct of trials in the wider research community is constantly evolving. ${ }^{14}$ The nature and pace of change in trial design can make it challenging for clinicians to understand how they may most effectively apply the evidence they generate to inform patient care. ${ }^{14}$

Various groups of people are interested in improving the quality of wound trials and research. People who have a stake in improving wound trials originate from diverse professions or backgrounds, although they can be broadly be categorised as patients, informal caregivers, informal patient networks, policymakers, academics/researchers, clinicians, and industry enterprise employees. The relationships between these different groups have at times been fraught with tension due to differing perspectives and commercial interests, specifically with regard to the use of evidence to inform practice, which affects the quality of wound care that patients receive. ${ }^{8,10,16}$ From an intellectual perspective, each group of people interested in improving the quality of wound trials can be considered a community of practice. ${ }^{17-20}$ This conceptualisation is appropriate because people who belong to the research community decide what may be considered a good trial. ${ }^{14}$ Therefore, it is important to establish what a community of practice is and how it is relevant to improving wound trials.

\section{Communities of practice}

A community of practice is a group of people who form relationships with one another based on a shared interest in improving some aspect of their practice, who work together, and who utilise their collective expertise to achieve a shared goal. ${ }^{18-20}$ Many different groups of people are interested in improving wound care, including surgeons, doctors, nurses, physiotherapists, and patients. Consequently, each of these groups can be considered a community of practice in its own right. People who belong to a formal or informal community of practice learn from one another as they use their shared expertise to achieve their overarching goals. ${ }^{17,18,20}$ Some examples of knowledge sharing between professional and patient groups may be found in wound care centres of excellence and wound care clubs. ${ }^{21,22}$

Over time, the people within a community of practice develop a shared identity and a set of values that can establish boundaries in collaborative work. ${ }^{19,20,23}$ Boundaries between people who belong to different professions and groups can be an impediment to the adoption of a collaborative evidence-based approach to delivering patientcentred wound care. ${ }^{68,10,16,24}$ The concept of a community of practice has been applied to refer to several aspects, ${ }^{25}$ and it is important that its relation to improving wound trials and research is clarified. In this paper, a community of practice refers to people who hold differing values as a result of their professions or backgrounds but nevertheless share the common interest of improving wound trials and research. 


\section{The Wounds Research Network}

A critical mass of researchers, academics clinicians, and patients in the UK have undertaken a wide range of innovative trials in pressure ulcers, ${ }^{26,27}$ leg ulcers, ${ }^{28-30}$ burns, ${ }^{31}$ and other types of wounds. ${ }^{32-37}$ The Tissue Viability Society created the WReN (https://woundsrn.org/) in 2015 to provide an interprofessional cross-speciality forum where people may share their knowledge, expertise, and insights regarding wound trials and research. The WReN offers opportunities to people from diverse backgrounds to further develop their knowledge and expertise in conducting high-quality wound trials and research regardless of their levels of expertise. Therefore, $\mathrm{WReN}$ is a community of practice that has helped overcome some research-related barriers to collaboration that exist between various professions and specialities in the UK.

Trials in any aspect of healthcare can be improved through more efficient reporting, methods, or regulation. ${ }^{1-3,14,15}$ However, the notion of improving the design and conduct of trials through a unifying community of practice such as WReN has not been previously reported. As such, exploring the benefits of a community of practice approach to improving wound trials and research (e.g., WReN) in other nations is worthwhile. A pragmatic first step towards achieving universal health coverage in wound care may, perhaps, involve the creation of national research communities of practice that focus on improving the quality of wound trials and research.

\section{CONCLUSION}

This paper has considered the challenges that exist with regard to improving trials to generate knowledge that clinicians may utilise to achieve universal health coverage in wound care. This paper has explored the case of the WReN, which functions as a community of practice that brings together people in the UK to improve wound trials and research. The WReN is an example of how a national research community of practice may facilitate interprofessional and cross-speciality collaboration as well as improvement in wound trials. National research communities of practice can help overcome the boundaries between various professions and groups of people that hinder teamwork in wound trials and research. The author hopes this paper inspires an international audience of people interested in improving wound trials to work collaboratively with others in a national research community of practice to achieve universal health coverage.

\section{IMPLICATIONS FOR FUTURE PRACTICE}

- Wound trials and research must be improved to generate knowledge that informs patient care at a national level.

- A national wounds research community of practice can provide a forum for shared learning and collaboration among people from diverse backgrounds.

\section{FURTHER RESEARCH}

- The effectiveness of research communities of practice in improving trials' design and conduct must be established in future research.

॥ It is important that future research consider other approaches to improving trials that acknowledge the social and collaborative nature of research in a context with rapidly evolving methodological innovations.
REFERENCES

1. Yordanov $Y$, Dechartres A, Porcher R, Boutron I, Altman DG, Ravaud P. Avoidable waste of research related to inadequate methods in clinical trials. BMJ 2015 Mar 24;350:h809.

2. Yordanov $Y$, Dechartres A, Atal I, Tran V-T, Boutron I, Crequit $P$, et al. Avoidable waste of research related to outcome planning and reporting in clinical trials. BMC Medicine 2018 Jun 11;16(1):87.

3. Dechartres A, Trinquart L, Atal I, Moher D, Dickersin $\mathrm{K}$, Boutron I, et al. Evolution of poor reporting and inadequate methods over time in 20920 randomised controlled trials included in Cochrane reviews: Research on research study. BMJ 2017 Jun 8;357:j2490.

4. Moher D, Glasziou P, Chalmers I, Nasser M, Bossuyt PMM, Korevaar DA, et al. Increasing value and reducing waste in biomedical research: Who's listening? The Lancet $2016 \mathrm{Sep}$ 27;387(10027): 1573-86.

5. Webb R. Low-quality evidence from RCTs is not giving us answers. J Wound Care 2017 Sep 2;26(9):517.

6. Cutting KF, White RJ, Legerstee R. Evidence and practical wound care - An all-inclusive approach. Wound Medicine 2017 Feb 21;16(Supplement C):40-5.
7. Samuriwo R. Letters: Response to 'Low quality evidence from RCTs is not giving us answers'. J Wound Care 2017 Nov; 26(11):700-1.

8. Pagnamenta $F$, Lhussier M. Viewing dressing evaluation through a pragmatic lens: The application of Dewey's experimentalism in the development of evidence for dressing selection. J Eval Clin Pract 2018 Oct;24(5):988-94.

9. Lockyer S, Hodgson R, Dumville J, Cullum N. 'Spin' in wound care research: The reporting and interpretation of randomized controlled trials with statistically non-significant primary outcome results or unspecified primary outcomes. Trials 2013 Nov 6; 14(1):371.

10. Madden M. Alienating evidence based medicine vs. innovative medical device marketing: A report on the evidence debate at a Wounds conference. Soc Sci Med 2012 Jun;74(12):2046-52.

11. Braithwaite J. Changing how we think about healthcare improvement. BMJ 2018 May $17 ; 361: \mathrm{k} 2014$

12. Woods DD, Branlat $M$. Basic patterns in how adaptive systems fail. In: Hollnagel E, Paries J, Woods D, Wreathall $J$, editors. Resilience engineering in practice: A guide book. Farnham: Ashgate; 2011. p. 127-44.
13. World Health Organization. Making fair choices on the path to universal health coverage. Final report of the WHO Consultative Group on Equity and Universal Health Coverage. Geneva, Switzerland: World Health Organization; 2014.

14. Bauchner H, Golub RM, Fontanarosa PB. Reporting and Interpretation of Randomized Clinical Trials. JAMA 2019 Aug 27;322(8):732-5.

15. Salman RA-S, Beller E, Kagan J, Hemminki E, Phillips RS, Savulescu J, et al. Increasing value and reducing waste in biomedical research regulation and management. The Lancet 2014 Jan 11;383(9912): 176-85.

16. Madden M, Stark J. Understanding the development of advanced wound care in the UK: Interdisciplinary perspectives on care, cure and innovation. J Tissue Viability 2019 May;28(2):107-14.

17. Wenger E. Communities of practice and social learning systems. Organization 2000 May $1 ; 7(2): 225-46$

18. Wenger $E$, Snyder W. Communities of practice: The organizational frontier. Harvard Business Review. 2000 January-February: 139-45.

19. Wenger $E$. Knowledge management is a donut: Shaping your knowledge strategy with communities of 


\section{REFERENCES}

practice. Ivey Business J $2004 \mathrm{Jan} / \mathrm{Feb}$. Available from https://iveybusinessjournal.com/publication/knowledge-management-as-a-doughnut/.

20. Wenger $E$, Trayner $B$, de Laat $M$. Promoting and assessing value creation in communities and networks: A conceptual framework. Herleen, Netherlands: Open University of the Netherlands; 2011.

21. Lindsay $\mathrm{E}$. How I got Leg Club up and running. $\mathrm{Br} J$ Nurs 2015 Sep 19;24:S4.

22. Government Opportunities. New £4million Welsh Wound Innovation Centre to deliver health and wealth benefits. 2013 Mar 21. Available from: http://www. govopps.co.uk/new-4m-welsh-wound-innovationcentre-to-deliver/

23. Kislov R, Walshe K, Harvey G. Managing boundaries in primary care service improvement: A developmental approach to communities of practice. Implementation Sci 2012 Oct 15;7(1):97.

24. Samuriwo $R$, Hannigan $B$. Wounds and mental health care: System thinking. Ment Health Rev J, in press.

25. Buckley H, Steinert Y, Regehr G, Nimmon L. When I say ... community of practice. Med Educ 2019 Mar 11;53(8):763-5.

26. Nixon J, Smith IL, Brown S, McGinnis E, VargasPalacios A, Nelson EA, et al. Pressure relieving support surfaces for pressure ulcer prevention (PRESSURE 2): Clinical and health economic results of a randomised controlled trial. EClinicalMedicine 2019 Sep 3;14:42-52.
27. Iglesias $C$, Nixon J Cranny $G$ Nelson EA, Hawkins $K$ Phillips $A$, et al. Pressure relieving support surfaces (PRESSURE) trial: Cost effectiveness analysis. BM. 2006 Aug 10;332:1416-8.

28. Gohel MS, Heatley F, Xinxue L, Bradbury A, Bulbulia $R$, Cullum $N$, et al. A randomized trial of early endovenous ablation in venous ulceration. $\mathrm{N}$ Engl J Med 2018 May 31;378(22):2105-14.

29. Ashby RL, Gabe R, Ali S, Saramago P, Chuang LH, Adderley $U$, et al. VenUS IV (venous leg ulcer study IV) - Compression hosiery compared with compression bandaging in the treatment of venous leg ulcers: A randomised controlled trial, mixed-treatment comparison and decision-analytic model. Health Technol Assess 2014 Sep; 18(57): 1-293.

30. White J, Ivins N, Wilkes A, Carolan-Rees G, Harding KG. Non-contact low-frequency ultrasound therapy compared with UK standard of care for venous leg ulcers: A single-centre, assessor-blinded, randomised controlled trial. Int Wound J 2016 Oct; 13(5):833-42.

31. Moiemen N, Mathers J, Jones L, Bishop J, Kinghorn $P$, Monahan $M$, et al. Pressure garment to prevent abnormal scarring after burn injury in adults and children: The PEGASUS feasibility RCT and mixedmethods study. Health Technol Assess 2018 Jun $29 ; 22(36) 1-162$.

32. Pinkney TD, Calvert $M$, Bartlett $D C$, Gheorghe $A$ Redman V, Dowswell G, et al. Impact of wound edge protection devices on surgical site infection after laparotomy: Multicentre randomised controlled tria (ROSSINI Trial). BMJ 2013 July 31;347:f4305.
33. Blazeby J Andronis L Coast J, Donovan J, Draycott $T$ Gooberman-Hill R, et al. The Bluebelle Study: A feasibility study of complex, simple and absent wound dressings in elective and unplanned surgery - Phase A protocol. Bristol: University Hospitals Bristol NHS Foundation Trust; 2015.

34. Smith S, Pearce L, Newton K, Barrow P, Smith J, Hancock L. PTU-210 Packing of perianal abscess cavities (PPAC) study: A multi-centre observational feasibility study, interim analysis. Gut 2015 June;64(Suppl 1):A155.1-A155.

35. Knight R, Spoors LM, Costa ML, Dutton SJ. Wound healing in surgery for trauma (WHIST): Statistical analysis plan for a randomised controlled trial comparing standard wound management with negative pressure wound therapy. Trials $2019 \mathrm{Mar}$ 28;20(1):186.

36. Costa ML, Achten J, Bruce J, Tutton E, Petrou S, Lamb SE, et al. Effect of negative pressure wound therapy vs standard wound management on

12-month disability among adults with severe open fracture of the lower limb: The WOLLF randomized clinical trial. JAMA 2018 Jun 12;319(22):2280-8.

37. Mehta S, Cro SC, Coomber B, Rolph R, Cornelius V Farhadi J. A randomised controlled feasibility trial to evaluate local heat preconditioning on wound healing after reconstructive breast surgery: The preHEAT trial. Pilot and Feasibility Studies 2019 Jan 11;5(1):5.

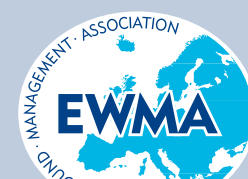

\section{Make a difference in clinical practice}

\section{Become a Member of EWMA}

\section{Benefits of your EWMA Membership:}

- You make a difference in clinical practice within wound management in Europe

- Right to vote and stand for EWMA Council

- EWMA Journal sent directly to you two times a year

- EWMA news and statements sent directly to you

- A discount on your registration fee for EWMA Conferences

- Right to apply for EWMA travel grants

- Yearly membership fee $€ 25$

- Yearly membership fee for members of cooperating organisations $€ 10$

- Please register to become a member here: www.ewma.org 